\title{
Conservative Treatment Versus Appendectomy for Acute Uncomplicated Appendicitis
}

\author{
Emad Hokkam ${ }^{1,2}$, Abdelaziz Gonna ${ }^{3}$, Aly Saber ${ }^{4}$, Ossama Zakaria ${ }^{1,5}$, Abdulhameed Alhazmi ${ }^{2}$ \\ ${ }^{1}$ Department of Surgery, Faculty of Medicine, Suez Canal University, Ismailia, Egypt \\ ${ }^{2}$ Department of Surgery, Faculty of Medicine, Jazan University, Jazan, Saudia Arabia \\ ${ }^{3}$ Department of Surgery, Jazan General Hospital, Jazan, Saudia Arabia \\ ${ }^{4}$ Department of Surgery, Port-Fouad General Hospital, Port-Fouad, Egypt \\ ${ }^{5}$ Department of Surgery, Faculty of Medicine, King Faisal University, Saudia Arabia
}

Email address:

ehokkam@gmail.com (E. Hokkam), alysaber54@gmail.com (A. Saber)

\section{To cite this article:}

Emad Hokkam, Abdelaziz Gonna, Aly Saber, Ossama Zakaria, Abdulhameed Alhazmi. Conservative Treatment Versus Appendectomy for Acute Uncomplicated Appendicitis. Journal of Surgery. Special Issue: Gastrointestinal Surgery: Recent Trends.

Vol. 4, No. 2-1, 2016, pp. 27-30. doi: 10.11648/j.js.s.2016040201.16

\begin{abstract}
Background: For more than 100 years, surgeons have been successfully performing appendectomy to treat acute appendicitis. However; there is recent trend to shift towards a more conservative approach. This work aimed to assess the nonoperative management in the treatment of acute uncomplicated appendicitis. Methods: One hundred and sixteen patients with uncomplicated acute appendicitis were enrolled into the study. They were divided into two groups (Group A \& Group B). Patients in Group A were subjected to non-operative management with antibiotics while patients in Group B were subjected to appendectomy. All patients were evaluated at hospital discharge, at 30-days and at a median follow-up on year. The primary outcome was the success rate of the non-operative management. Secondary outcomes were the difference of length of hospitalization, time to return to normal activity, and quality-of-life measures between both groups. Results: The success rate of non-operative strategy was $93.3 \%$ (42 of 45) at hospital discharge, 88.8\% (40 of 45) at 30-days and $82.2 \%$ (37 of 45 ) at a median follow-up of one year. Patients in Group A have a significantly shorter time to return to normal activities. They reported higher quality of life scores. The length of hospitalization was significantly shorter in Group B. Conclusion: Giving intravenous antibiotics to some patients with uncomplicated acute appendicitis instead of having them undergo surgery may be safe and effective.
\end{abstract}

Keywords: Appendicitis, Antibiotics, Conservative, Appendectomy

\section{Introduction}

Surgeons remove the appendix to treat acute appendicitis since the late of 1800 s, even though an inflamed appendix sometimes gets better on its own. Some reports suggest that trying intravenous antibiotics first works as well as surgery for some people. Antibiotics alone successfully treated appendicitis $63 \%$ of the time [1-4].

People who received antibiotics instead of surgery were $39 \%$ less likely than those who underwent surgery to develop complications such as a perforated appendix, peritonitis, or infection around the appendectomy incision $[5,6]$. On the other hand; about $20 \%$ of those treated with antibiotics had a return of pain or other symptoms and needed to go back the hospital; some of these had serious infections [7]. The cost-effectiveness comparison of operative and non-operative strategies for patients with acute appendicitis has not been fully investigated [8].

Authors who deny the usefulness of conservative management for uncomplicated acute appendicitis claim that it is difficult to distinguish between complicated and uncomplicated appendicitis, and appendicectomy is associated with limited morbidity [9]. Moreover; given the lifetime incidence of appendicitis is approximately $8 \%$, a move from predominantly surgical management of appendicitis to antibiotic therapy has the potential to impact on many patients. This impact might be direct, through outcomes associated with the condition itself, or indirect, through the generation and transmission of antibiotic resistance [10-12].

The aim of this study is to assess the effectiveness and 
safety of antibiotics in the treatment of uncomplicated acute appendicitis.

\section{Methods}

This is a prospective non-randomized study of patients with any age who have acute uncomplicated appendicitis. The patients were divided into two groups (Group A \& Group B). Patients in Group A were subjected to non-operative management with antibiotics while patients in Group B were subjected to appendectomy. The study was carried out between January 2012 to December 2014 in Jazan General Hospital, Jazan, Saudi Arabia.

The diagnosis of acute uncomplicated appendicitis with fewer than 48 hours of symptoms was made according to history, physical examination result, WBC count, and ultrasonographic findings showing evidence of non-ruptured appendicitis with an appendiceal diameter of $1.1 \mathrm{~cm}$ or less [13]. Exclusion criteria included suspicion of perforation, appendiceal mass, symptoms lasting more than 48 hours or previous non-operative treatment of acute appendicitis.

Enrolling into either group was depending on the choice of the patient or his/her family after clarification of both types of management and the possibility of turning to appendectomy at any time. An informed consent was taken from each patient or his/her family. Patients who did not improve within 24 hours were considered to have failed non-operative management and underwent appendectomy. Patients in Group B were evaluated at hospital discharge, at 30-days and at a median follow-up on year.

The primary outcome was the percentage of patients who were successfully treated non-operatively. Secondary outcomes were the difference of length of hospitalization, time to return to normal activity, and quality-of-life measures between both groups.

\section{Results}

The study included 116 patients with uncomplicated acute appendicitis. Forty five chose to follow the non-operative strategy (Group A) while seventy one chose to undergo appendectomy (Group B). There were no significant differences between the two groups as regards the socio-demographic characteristics, duration of complaint, presenting symptoms, or white blood cell counts (Table 1).

In Group B, the pathological analysis of the removed appendix demonstrated complications in $11.3 \%$ of patients $(n=8)$. Five appendices were perforated and three were gangrenous. The appendix was normal in $7.0 \%(n=5)$.

Fortunately; all patients in Group A could be followed up for one year. The success rate of non-operative strategy was $93.3 \%$ (42 of 45) at hospital discharge, $88.8 \%$ (40 of 45) at 30 -days and $82.2 \%$ (37 of 45$)$ at a median follow-up of one year. There were three patients shifted to appendectomy during their initial admission because of lack of improvement or clinical progression within 24 hours of antibiotic administration. The pathology of their appendices revealed acute suppurative appendicitis.

Table 1. Socio-demographic characteristics, clinical features and blood test in both groups.

\begin{tabular}{|c|c|c|c|}
\hline Characteristics & $\begin{array}{l}\text { Group A } \\
(n=45)\end{array}$ & Group B $(n=71)$ & $\begin{array}{l}P \\
\text { value }\end{array}$ \\
\hline Age in year, median & $35(20-43)$ & $28(17-40)$ & 0.48 \\
\hline Male, n(\%) & $29(64.4 \%)$ & $48(67.6 \%)$ & 0.33 \\
\hline $\begin{array}{l}\text { Duration of abdominal } \\
\text { pain in hours, median }\end{array}$ & $13(8-24)$ & $14(9-24)$ & 0.44 \\
\hline Fever, $\mathrm{n}(\%)$ & $12(26.6 \%)$ & $12(16.9 \%)$ & 0.32 \\
\hline Vomiting, n(\%) & $24(53.3 \%)$ & $29(40.8 \%)$ & 0.28 \\
\hline Diarrhea, n(\%) & $6(13.3 \%)$ & $34.2 \%)$ & 0.22 \\
\hline $\begin{array}{l}\text { White blood cell count, } \\
1,000 \text { cells } / \mathrm{mL} \text {, median }\end{array}$ & $13.7(9.4-14.7)$ & $14.0(10.8-14.9)$ & 0.35 \\
\hline
\end{tabular}

Two patients presented with recurrent abdominal pain within 30 days after being discharged. One of them came back after 7 days and the other after 22 days. Both of them were operated upon for appendicitis. None of them exhibited progression of his appendicitis to rupture or gangrene at the time of appendectomy. The pathology of first patient showed acute uncomplicated appendicitis while that of the second patient (after 22 days of discharge) showed normal appendix.

Three patients presented with clinical picture suggestive of acute appendicitis between 30 days after being discharged and approximately one year of follow up. The pathological study of their appendices revealed acute appendicitis.

Patients in Group A have a significantly shorter time to return to normal activities. The length of hospitalization was significantly longer in Group A (A median of 40 hours versus a median 23 hours). Patients in Group Areported higher quality of life scores (measured by WHO standardized quality of life questionnaire). The comparison between both groups as regards the secondary outcomes is shown in Table 2 .

Table 2. Secondary outcomes in both groups.

\begin{tabular}{llll}
\hline Outcomes & $\begin{array}{l}\text { Group A } \\
(\mathbf{n = 4 5 )}\end{array}$ & $\begin{array}{l}\text { Group B } \\
(\mathbf{n = 7 1 )}\end{array}$ & P value \\
\hline $\begin{array}{l}\text { Days to return to normal } \\
\text { activities, median }\end{array}$ & $3.0(2-6)$ & 17.3(10-22) & $<0.0001$ \\
$\begin{array}{l}\text { Length of hospitalization (in } \\
\text { hours) }\end{array}$ & $40(29-44)$ & 23(18-36) & $<0.0001$ \\
*QOL questionnaire score & $95(88.1-98.3)$ & $86.8(81.1-92.7)$ & 0.011 \\
\hline
\end{tabular}

*WHO standardized quality of life questionnaire

\section{Discussion}

Traditionally, any patient presenting with acute uncomplicated appendicitis is referred for urgent surgery. The greatest advance of antibiotic production and success of discovery of newly highly effective broad-spectrum antibiotics allow for more conservative approach in management of such cases [14]. Several recent European randomized controlled trials suggest that therapy with antibiotics alone is a safe treatment option for appendicitis. 
Although antibiotic treatment may fail in some patients and there is a risk of recurrence, the surgically treated patients are subjected to the risks of operative morbidity and mortality [15-20].

In a recent systematic review and meta-analysis conducted by Liu and Fogg 2011, they analyzed six reports comprised of 1,201 patients. They reported that the mean antibiotic failure rate was $6.9 \%$ (range $0 \%$ to $11.8 \%$ ) and the mean recurrent appendicitis rate was $14.2 \%$ (range $5.3 \%$ to $35 \%$ ). A mean of $7.3 \%$ of patients (range $3.2 \%$ to $10 \%$ ) had a normal appendix at appendectomy. Also they found that complications were considerably less likely to occur with antibiotic treatment than with appendectomy. Major surgical complications included enterocutaneous fistula and reoperation [21]. These results and conclusion is largely match with that of the current study. Another meta-analysis carried out by Varadhan and his colleague in 2012 demonstrated that non-operative management had a pooled success rate of $63 \%$ at 1 year, with considerably lower risks of complications and no difference in the risk of developing complicated appendicitis. However; this study compared the two management strategies at one year in contrast to the current study which compared it at three intervals; at discharge, at 30 days and at one year [4]. Arguments against this initial antibiotic therapy include the risk of recurrence, bad compliance with medical therapy, increased length of hospitalization, patient anxiety associated with subsequent episodes of abdominal pain, and the relatively low morbidity of appendectomy [22].

In 2010; Shindoh J, et al. studied the predictive factors for negative outcomes in initial non-operative management of suspected appendicitis. He concluded that, these factors include fecaliths, fluid collections, and an appendiceal diameter greater than $1.1 \mathrm{~cm} \mathrm{[23].} \mathrm{The} \mathrm{risk} \mathrm{of} \mathrm{fecalith} \mathrm{can} \mathrm{be}$ rolled out by routine imaging studies, such as computed tomography or ultrasonography which allow risk stratification because fecaliths, phlegmons, and abscesses [24].

In conclusion; the majority of patients with uncomplicated acute appendicitis can be successfully treated by antibiotics instead of undergo appendectomy. This conservative approach results in early return to normal activity, and better quality of life measures. However; other factors like cost effectiveness and long term follow up $(<$ one year) should be further investigated.

\section{References}

[1] Minneci PC, Sulkowski JP, Nacion KM, Mahida JB, Cooper JN, Moss RL, Deans KJ. Antibiotics alone as an alternative therapy for uncomplicated pediatric appendicitis. Journal of the American College of Surgeons. 2014 Oct; 219(4): 27.

[2] Hennelly KE, Bachur R. Appendicitis update. Current Opinion in Pediatrics. 2011June; 23(3): 281-285.

[3] Fitzmaurice GJ, Billy McWilliams B, Epanomeritakis E. Antibiotics versus appendectomy in the management of acute appendicitis: a review of the current evidence. Canadian Journal of Surgery. 2011 Oct; 54(5): 307-314.
[4] Varadhan KK, Neal KR, Lobo DN. Safety and efficacy of antibiotics compared with appendectomy for treatment of uncomplicated acute appendicitis: meta-analysis of randomized controlled trials. BMJ. 2012 Apr 5; 344: e2156.

[5] Andersson RE. The natural history and traditional management of appendicitis revisited: spontaneous resolution and predominance of prehospital perforations imply that a correct diagnosis is more important than an early diagnosis. World $\mathrm{J}$ Surg. 2007; 31: 86e92.

[6] Varadhan KK, Humes DJ, Neal KR, Lobo DN. Antibiotic therapy versus appendectomy for acute appendicitis: a meta-analysis. World J Surg. 2010 Feb; 34(2): 199-209.

[7] Ansaloni L, Catena F, Coccolini F, Ercolani G, Gazzotti F, Pasqualini E, Pinna AD. Surgery versus conservative antibiotic treatment in acute appendicitis: a systematic review and meta-analysis of randomized controlled trials. Dig Surg. 2011; 28(3): 210-21.

[8] Wilms IM, de Hoog DE, de Visser DC, Janzing HM. Appendectomy versus antibiotic treatment for acute appendicitis. Cochrane Database Syst Rev. 2011 Nov 9; (11): CD008359.

[9] Mason RJ, Moazzez A, Sohn H, Katkhouda N. Meta-analysis of randomized trials comparing antibiotic therapy with appendectomy for acute uncomplicated (no abscess or phlegmon) appendicitis. Surg Infect (Larchmt). 2012 Apr; 13(2): 74-84.

[10] Nagpal K, Udgiri N, Sharma N, Curras E, Cosgrove JM, Farkas DT: Delaying an appendectomy: is it safe? Am Surg 2012, 78(8): 897-900.

[11] Vons C, Barry C, Maitre S, Pautrat K, Leconte M, Costaglioli B, Karoui M, Alves A, Dousset B, Valleur P, Falissard B, Franco D. Amoxicillin plus clavulanic acid versus appendicectomy for treatment of acute uncomplicated appendicitis: an open-label, non-inferiority, randomised controlled trial. Lancet. 2011 May 7; 377(9777): 1573-9.

[12] Sakorafas GH, Mastoraki A, Lappas C, Sampanis D, Danias N, Smyrniotis V. Conservative treatment of acute appendicitis: heresy or an effective and acceptable alternative to surgery? European journal of gastroenterology \&hepatology. 2011 Feb; 23(2): 121-7.

[13] Pinto F, Pinto A, Russo A, Coppolino F, Bracale R, Fonio P, Macarini L, Giganti M. Accuracy of ultrasonography in the diagnosis of acute appendicitis in adult patients: review of the literature. Crit Ultrasound J. 2013 Jul 15; 5 Suppl 1: S2.

[14] Hansson J, Körner U, Khorram-Manesh A, Solberg A, Lundholm K. Randomized clinical trial of antibiotic therapy versus appendicectomy as primary treatment of acute appendicitis in unselected patients. Br J Surg. 2009 May; 96(5): 473-81.

[15] Liu ZH, Li C, Zhang XW, Kang L, Wang JP. Meta-analysis of the therapeutic effects of antibiotic versus appendectomy for the treatment of acute appendicitis. ExpTher Med. 2014 May; 7(5): 1181-1186.

[16] Shin CS, Roh YN, Kim JI. Delayed appendectomy versus early appendectomy in the treatment of acute appendicitis: a retrospective study. World J Emerg Surg. 2014 Jan 21; 9(1): 8.

[17] Udgiri N, Curras E, Kella VK, Nagpal K, Cosgrove J. Appendicitis, is it an emergency? AmSurg 2011, 77(7): 898-901. 
[18] Papandria D, Goldstein SD, Rhee D, Salazar JH, Arlikar J, Gorgy A, Ortega G, Zhang Y, Abdullah F. Risk of perforation increases with delay in recognition and surgery for acute appendicitis. J Surg Res. 2013 Oct; 184(2): 723-9.

[19] Minneci PC, Sulkowski JP, Nacion KM, Mahida JB, Cooper JN Moss RL, Deans KJ. Feasibility of a non-operative management strategy for uncomplicated acute appendicitis in children. Journal American College of Surgeons. 2014; 219: $272 \mathrm{e} 279$.

[20] Kirby A, Hobson RP, Burke D, Cleveland V, Ford G, West RM. Appendicectomy for suspected uncomplicated appendicitis is associated with fewer complications than conservative antibiotic management: A meta-analysis of post-intervention complications. Journal of Infection (2015) 70, 105e110.

[21] Liu K, Fogg L. Use of antibiotics alone for treatment of uncomplicated acute appendicitis: a systematic review and meta-analysis. Surgery 2011; 150: 673e683.
[22] Horst JA, Trehan I, Warner BW, Cohn BG. Can children with uncomplicated acute appendicitis be treated with antibiotics instead of an appendectomy? Annals of emergency medicine. 2015Feb 25. pii: S0196-0644(15)00085-2.

[23] Shindoh J, Niwa H, Kawai K, Ohata K, Ishihara Y, Takabayashi N, Kobayashi R, Hiramatsu T. Predictive factors for negative outcomes in initial non-operative management of suspected appendicitis. J Gastrointest Surg 2010; 14: 309e314.

[24] Ein SH, Langer JC, Daneman A. Non operative management of pediatric ruptured appendix with inflammatory mass or abscess: presence of an appendicolith predicts recurrent appendicitis. J Pediatr Surg 2005; 40: 1612e1615. 